\section{Contrast sensitivity and binocular brightness: Dioptic and dichoptic luminance conditions}

\author{
RANDOLPH BLAKE, BRUNO BREITMEYER \\ and MARC GREEN \\ Cresap Neuroscience Laboratory, Northwestern University \\ Evanston, Illinois 60201
}

Several studies have shown that the spatial contrast sensitivity function (CSF) changes with background adaptation level (Kelly, 1977); an example of this effect is shown in Figure 1, where open circles and open squares plot monocular contrast thresholds measured at two adaptation levels differing by 1.0 $\log$ unit. These data, which were obtained using an adjustment method, are quite representative of the characteristic depression of the CSF which obtains as the space average luminance is lowered.

This adaptation level effect is generally attributed to changes in the gain mechanism of neurons at very early stages in visual processing (Enroth-Cugell \& Robson, 1966; Kelly, 1977). Yet there are several types of psychophysical evidence which suggest that adaptation level effects can involve more central mechanisms. For one thing, monocular detection thresholds for small light flashes can be influenced by background fields presented to the contralateral eye (Boynton, 1961; Prestrude, 1976), and a similar interocular effect has been reported for flicker discrimination (Lipkin, 1962). Also, the work of Levelt (1965) very clearly demonstrates that the apparent brightness of dichoptically viewed displays of unequal luminance assumes some value intermediate between the brightness of the two half-images. Finally, it has been shown, in human amblyopes, that the visual acuity in the amblyopic eye can be enhanced by reductions in luminance of a contour-free field viewed by the nonamblyopic eye (von Noorden $\&$ Leffler, 1966). All of these results indicate that the luminance of a homogeneous field viewed by one eye can influence visual performance of the contralateral eye. Intrigued by these findings, we felt it worthwhile to test the possibility that adaptation level effects on the CSF in normal observers can be influenced by a manipulation which taps central (i.e., binocular) mechanisms.

\section{Methods}

Monocular contrast thresholds were measured for sinusoidal,

Supported by a Research Grant (EY01596) and Career Development Award (EY00106 to R.B.) from the National Institutes of Health. Send reprint requests to Randolph Blake, Cresap Neuroscience Laboratory, Northwestern University, Evanston, Illinois 60201 . B. Breitmeyer was on leave from the University of Houston; M. Green was on leave from the University of California, Berkeley.

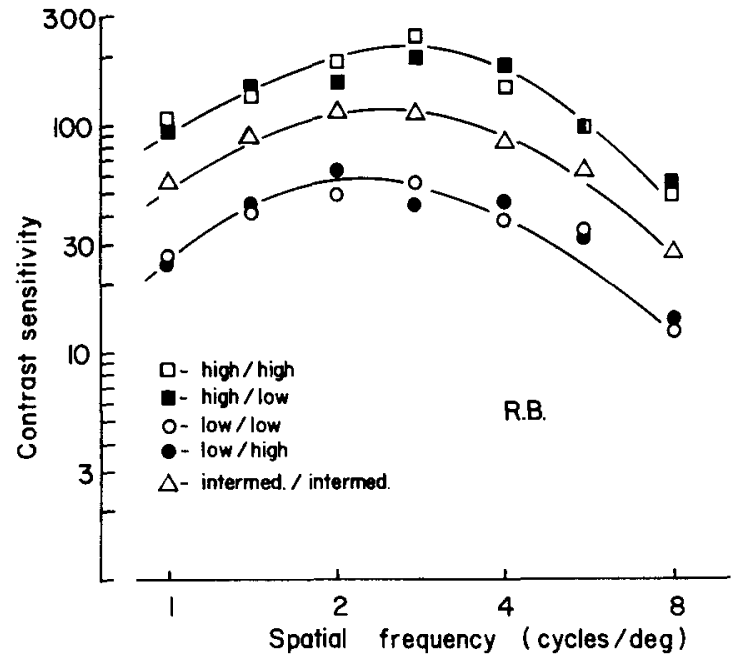

Figure 1. Contrast sensitivity (inverse of threshold) as a function of spatial frequency for dioptic (equal luminance to the two eyes) and dichoptic (unequal luminance to the two eyes) stimulation. Each point represents the arithmetic mean of six threshold settings made by the observer's controlling a 10-turn potentiometer to adjust the contrast of a grating to threshold visibility; the standard error about these values typically was .015 log units or less. These particular results are for observer R.B., and they are representative of the results obtained from other observers. The smooth curves were fitted by eye.

vertical grating patterns which were electronically generated on a cathode-ray tube (CRT) masked down to a circular region 5 deg in diameter. The average luminance of this test field did not change with spatial frequency or contrast. The nontested eye viewed a second CRT of the same dimensions, but this field always appeared uncontoured. The two CRTs were viewed via a mirror stereoscope, and the observer saw the displays through 3-mm artificial pupils while the head was steadily positioned on a dental impression board. Space average luminance of either field could be varied by placing neutral density filters immediately behind the artificial pupils. Details of the apparatus and electronics appear elsewhere (Blake \& Cormack, 1979). The observers were the authors, all of whom have excellent uncorrected acuity and good stereopsis. For each observer, great care was taken in aligning the two displays in binocular coincidence, to insure comfortable fusion and centered viewing through the artificial pupils.

\section{Results and Discussion}

In one experiment, a method of adjustment procedure was used to measure monocular contrast thresholds. One set of measurements was made under two dichoptic conditions, one in which the tested eye received $7 \mathrm{~cd} / \mathrm{m}^{2}$ and the nontested eye received $.7 \mathrm{~cd} / \mathrm{m}^{2}$ (the "high/low" condition) and the other in which the tested eye received $.7 \mathrm{~cd} / \mathrm{m}^{2}$ and the nontested eye received $7 \mathrm{~cd} / \mathrm{m}^{2}$ ("low/high"). A second set of measurements was made under dioptic conditions in which both tested and nontested eyes received either $7 \mathrm{~cd} / \mathrm{m}^{2}$ ("high/high") or $.7 \mathrm{~cd} / \mathrm{m}^{2}$ ("low/low"). All observers reported that the display appeared brighter in the high/high condition than in 
the low/low condition. When the two fields were of unequal luminance (low/high and high/low), observers reported a stable percept of intermediate brightness. This observation is consistent with earlier work (Levelt, 1965) showing that the binocular impression of brightness depends on the contribution from each eye. Contrast thresholds, on the other hand, were found to depend exclusively on the luminance of the display viewed by the tested eye and not on the observer's brightness impression.

Results for the four test conditions are shown in Figure 1. Although apparent brightness in these two differed, the high/high and high/low thresholds were similar. Likewise, thresholds were similar for the two conditions in which the tested eye received low luminance (low/low and low/high). Note that thresholds for the high/low and low/high conditions differed by about $.5 \mathrm{log}$ unit even though binocular brightness impression was equivalent for the two conditions. We have replicated this pattern of results for the low/ low and low/high conditions using a two-alternative forced-choice procedure, wherein the observer had to indicate in which one of two successive 1-sec intervals the monocular test grating appeared. Percent-correct performance for the two conditions never differed by more than $3 \%$, which is not close to statistical significance.

Our results show, then, that contrast sensitivity does not depend on binocular brightness, suggesting that adaptation level is determined by monocular mechanisms. It is possible, however, that the unequal luminance pairs, although appearing different in brightness from the equal luminance conditions, failed to create an adaptation level sufficiently different to alter contrast sensitivity. To test this possibility, we adjusted the brightness of an equal luminance pair to match that of the two unequal luminance pairs; this maneuver yielded a dioptic luminance of $3.7 \mathrm{~cd} / \mathrm{m}^{2}$, which is close to the arithmetic mean of the dichoptic values (Levelt, 1965). We remeasured thresholds at this adaptation level and found intermediate sensitivity, as shown by the open triangles in Figure 1. Looking at all three curves, it is interesting to note that sensitivity changes in a manner predicted by the DeVries-Rose law (Kelly, 1977).
This pattern of results indicates that it is the adaptation level of the eye receiving the test grating alone that determines contrast sensitivity for that eye. We find no evidence for an interocular adaptation level effect of the kind reported for briefly flashed lights (Lipkin, 1962; Prestrude, 1976). Our results are consistent with the idea that peripheral gain mechanisms, probably retinal in locus, mediate the progressive enhancement in contrast sensitivity with increasing background intensity. This is not to say, however, that central mechanisms are not involved in grating detection, for there is solid psychophysical evidence for binocular interactions in contrast sensitivity (Blake \& Levinson, 1977; Legge, 1979). The present arguments pertain only to the locus of neural mechanisms underlying the effects of steady background illumination.

\section{REFERENCES}

Blake, R., \& Cormack, R. Psychophysical evidence for a monocular visual cortex in stereoblind humans. Science, 1979, 203, 274-275.

Blake, R., \& Levinson, E. Spatial properties of binocular neurones in the human visual system. Experimental Brain Research, 1977, 27, 221-232.

Boynton, R. Some temporal factors in vision. In W. A. Rosenblith (Ed.), Sensory communication. Cambridge: M.1.T. Press, 1961.

Enroth-Cugell, C., \& Robson, J. G. The contrast sensitivity of retinal ganglion cells of the cat. Journal of Physiology, 1966, 187, 517-551.

Kelly, D. Visual contrast sensitivity. Optica Acta, 1977, 24, 107-129.

LEGGE, G. Spatial frequency masking in human vision: Binocular interactions. Journal of the Optical Society of America, 1979, 69, 838-846.

LEVELt, W. J. M. On binocular rivalry. Soesterberg, The Netherlands: Institute for Perception RVO-TNO, 1965.

LIPKIN, B. S. Monocular flicker discrimination as a function of the luminance and area of contralateral steady light. I. Luminance. Journal of the Optical Society of America, 1962, 52, 1287-1295.

Prestrude, A. M. The interocular light adaptation effect at different retinal locations. Vision Research, 1976, 16, 1071-1076.

von Norden, G., \& Leffle R, M. B. Visual acuity in strabismus amblyopia under monocular and binocular conditions. Archives of Ophthalmology, 1966, 76, 172-177.

(Received for publication November 28, 1979; accepted November 29, 1979.) 